\title{
Volcanic ash from Iceland over Munich: mass concentration retrieved from ground-based remote sensing measurements
}

\author{
J. Gasteiger, S. Groß, V. Freudenthaler, and M. Wiegner \\ Meteorologisches Institut, Ludwig-Maximilians-Universität, München, Germany \\ Received: 5 October 2010 - Published in Atmos. Chem. Phys. Discuss.: 8 November 2010 \\ Revised: 18 February 2011 - Accepted: 7 March 2011 - Published: 11 March 2011
}

\begin{abstract}
Volcanic ash plumes, emitted by the Eyjafjallajökull volcano (Iceland) in spring 2010, were observed by the lidar systems MULIS and POLIS in Maisach (near Munich, Germany), and by a CIMEL Sun photometer and a JenOptik ceilometer in Munich. We retrieve mass concentrations of volcanic ash from the lidar measurements; spectral optical properties, i.e. extinction coefficients, backscatter coefficients, and linear depolarization ratios, are used as input for an inversion. The inversion algorithm searches for model aerosol ensembles with optical properties that agree with the measured values within their uncertainty ranges. The non-sphericity of ash particles is considered by assuming spheroids. Optical particle properties are calculated using the T-matrix method supplemented by the geometric optics approach. The lidar inversion is applied to observations of the pure volcanic ash plume in the morning of 17 April 2010. We find $1.45 \mathrm{~g} \mathrm{~m}^{-2}$ for the ratio between the mass concentration and the extinction coefficient at $\lambda=532 \mathrm{~nm}$, assuming an ash density of $2.6 \mathrm{~g} \mathrm{~cm}^{-3}$. The uncertainty range for this ratio is from $0.87 \mathrm{~g} \mathrm{~m}^{-2}$ to $2.32 \mathrm{~g} \mathrm{~m}^{-2}$. At the peak of the ash concentration over Maisach the extinction coefficient at $\lambda=532 \mathrm{~nm}$ was $0.75 \mathrm{~km}^{-1}$ (1-h-average), which corresponds to a maximum mass concentration of $1.1 \mathrm{mg} \mathrm{m}^{-3}$ ( 0.65 to $\left.1.8 \mathrm{mg} \mathrm{m}^{-3}\right)$. Model calculations show that particle backscatter at our lidar wavelengths $(\lambda \leq 1064 \mathrm{~nm})$, and thus the lidar retrieval, is hardly sensitive to large particles $(r \gtrsim 3 \mu \mathrm{m})$; large particles, however, may contain significant amounts of mass. Therefore, as an independent cross check of the lidar retrieval and to investigate the presence of large particles in more detail, we model ratios of sky radiances in the aureole of the Sun and compare them to measurements of the CIMEL. These ratios are sensitive to particles up to $r \approx 10 \mu \mathrm{m}$. This approach confirms the mass concentrations
\end{abstract}

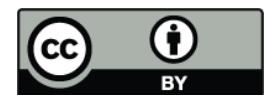

Correspondence to: J. Gasteiger (josef.gasteiger@lmu.de) from the lidar retrieval. We conclude that synergistic utilization of high quality lidar and Sun photometer data, in combination with realistic aerosol models, is recommended for improving ash mass concentration retrievals.

\section{Introduction}

Aerosol particles from volcanic eruptions can have strong impact on the radiation budget of the Earth's atmosphere. Therefore, as soon as the lidar technology became mature in the 1970's, stratospheric volcanic aerosols over Central Europe have been observed, including aerosols from the major eruptions of El Chichón and Pinatubo (Jäger, 2005). More recently Mattis et al. (2010) reported on multi-wavelength Raman lidar measurements of aerosols in the lower stratosphere over Europe from eruptions of different volcanoes. Although the concentration of stratospheric aerosols is usually very low, they can have notable impact on global climate because of their large scale dispersion and their long residence times which is on the order of months or several years. In contrast, the residence time of volcanic aerosols in the troposphere is only on the order of several days and its spatial distribution can be quite inhomogeneous, so that the assessment of their radiative effects is much more complicated.

During the eruption of the Eyjafjallajökull volcano (Iceland) in spring 2010, tropospheric ash plumes were advected to large areas in Europe. This offered a unique opportunity for aerosol science and remote sensing, in particular, because this was the first significant volcanic event in the affected areas since the start of aerosol lidar-observations. Although the Eyjafjallajökull eruption emitted only small amounts of volcanic ash compared to major volcanic eruptions in history, quite soon after the onset of the eruption, a further aspect beyond meteorology became apparent: Volcanic ash is critical for the flight safety of jet-driven aircrafts; engine failures occur if certain amounts of ash are melted and deposited

Published by Copernicus Publications on behalf of the European Geosciences Union. 
on critical parts of the engines (e.g., Casadevall, 1994; Pieri et al., 2002). For the genesis of such deposits, the mass concentration of the ash in the atmosphere is an important parameter. Consequently, as a measure of precaution, air traffic was closed in regions with volcanic ash concentrations exceeding certain thresholds (Gertisser, 2010). However, in the course of the eruption, a lack of operational measurements of mass concentrations became apparent. Nonetheless, the European Aerosol Research Lidar Network (EARLINET, e.g., Bösenberg et al., 2003) showed the potential of detecting volcanic ash plumes by networks of active remote sensing instruments (Sanderson, 2010). Reports concerning the dispersion of the plume were provided to the Volcanic Ash Advisory Centers on a hourly to daily basis.

For the assessment of flight safety impacts, the distinction between ash and non-ash particles is necessary. Non-ash particles of volcanic origin are usually liquid particles, predominantly originating from condensation of volcanic gases. Ash particles are solid particles with non-spherical shapes, consisting of glass and crystals from the magma and fragments from the walls of the volcano vent (Mather et al., 2003). The non-sphericity of ash particles allows one to distinguish ash from other aerosol types by means of polarization lidars (Sassen et al., 2007). Note, that measurements of scattering properties of samples of volcanic ash from different volcanoes were presented by Muñoz et al. (2004). For the interpretation of multi-wavelength lidar measurements of ash plumes, however, such measurements are not sufficient. Instead, knowledge from numerical simulations about the relationship between optical and microphysical particle properties is required, in particular, to cover the backscatter direction and the lidar-specific wavelengths, as well as the variability of aerosol properties.

Volcanic ash plumes from Eyjafjallajökull over the EARLINET station in Maisach (25 km northwest of Munich) were observed by the lidar systems MULIS and POLIS. Measurements started before the predicted arrival of the ash plume on 16 April 2010. Using these lidar systems a comprehensive set of optical properties of the volcanic ash was derived (Wiegner et al., 2011). These optical aerosol properties include the backscatter coefficient at three wavelengths, as well as the extinction coefficient and the linear depolarization ratio at two wavelengths.

The aim of this paper is to derive microphysical properties of the ash from these lidar measurements, considering the non-sphericity of the ash particles in the retrieval. Special emphasis is on the mass concentration because it is a critical parameter for flight safety. The optical characterization and the temporal development of the volcanic ash plumes over Maisach is the topic of a separate study (Groß et al., 2010). Continuous lidar measurements show that the maximum of the Eyjafjallajökull ash plume over Maisach in terms of backscatter coefficient occurred in the morning of 17 April 2010, thus the focus of this paper is on that date. It should be emphasized that in-situ measurements of the mass concentrations are not available for 17 April. The first airborne in-situ measurements over Germany were provided only on 19 April (Schumann et al., 2010b). Thus, the inversion of lidar data is the only option to retrieve mass concentrations in the German airspace for this most relevant stage of the Eyjafjallajökull episode. This fact is a strong motivation for us to attempt this inversion though it cannot be expected that the uncertainties are small. For this reason, we additionally perform an independent consistency check of the lidar retrieval results using sky radiances that were measured in the aureole of the Sun at the AERONET site in Munich. Colocated measurements of a ceilometer prove the similarity of vertical and temporal aerosol distributions in Munich and Maisach.

The paper is organized as follows: First we give an overview of the Eyjafjallajökull activity and the meteorological situation. In Sect. 3 we describe our lidar systems and our approach for the inversion of mass concentrations from lidar data. The inversion is applied to lidar measurements of 17 April. The next section is devoted to the consistency check of the lidar inversion results by using Sun photometer measurements. The paper ends with a summary of the findings and conclusions.

\section{Volcanic activity and meteorological situation}

The eruption of the Eyjafjallajökull volcano $\left(63.63^{\circ} \mathrm{N}\right.$, $19.61^{\circ} \mathrm{W}$ ) started on 20 March 2010 (Gertisser, 2010). The first phase was characterized by an effusive eruption that produced lava flows on the ground and only minor emissions into the atmosphere. On 14 April an explosive eruption of the volcano started. It started beneath a glacier, which intensified its explosivity because water vapor was produced by the interaction of hot volcanic material with ice. The ash plumes reached heights of about $8 \mathrm{~km}$, thus mainly stayed within the troposphere. The explosive eruption continued with varying intensity for over one month.

The wind field advected volcanic ash to parts of Central Europe. Volcanic ash reached northern Germany in the night from 15 to 16 April (Flentje et al., 2010; Ansmann et al., 2010) and first traces of ash over Maisach were detected by MULIS at about 17:00 UTC on 16 April between $5 \mathrm{~km}$ and $7 \mathrm{~km}$ above ground (Fig. 1). The maximum of the ash layer over Maisach, in terms of backscatter coefficient, was observed between 06:00 UTC and 09:00 UTC on 17 April in a height of $2.0-2.4 \mathrm{~km}$. The ash layer was separated from the boundary layer aerosols until the afternoon of 17 April, when mixing of both aerosol types was observed.

Backward trajectories (Draxler and Rolph, 2010) for the ash plume over Maisach in the morning of 17 April (not shown) indicate that the transport of the ash from the volcano to the measurement site took approximately 45 to $50 \mathrm{~h}$. Radiosondes of the German Weather Service (DWD) measured relative humidities in the ash layer in the range from $16 \%$ 


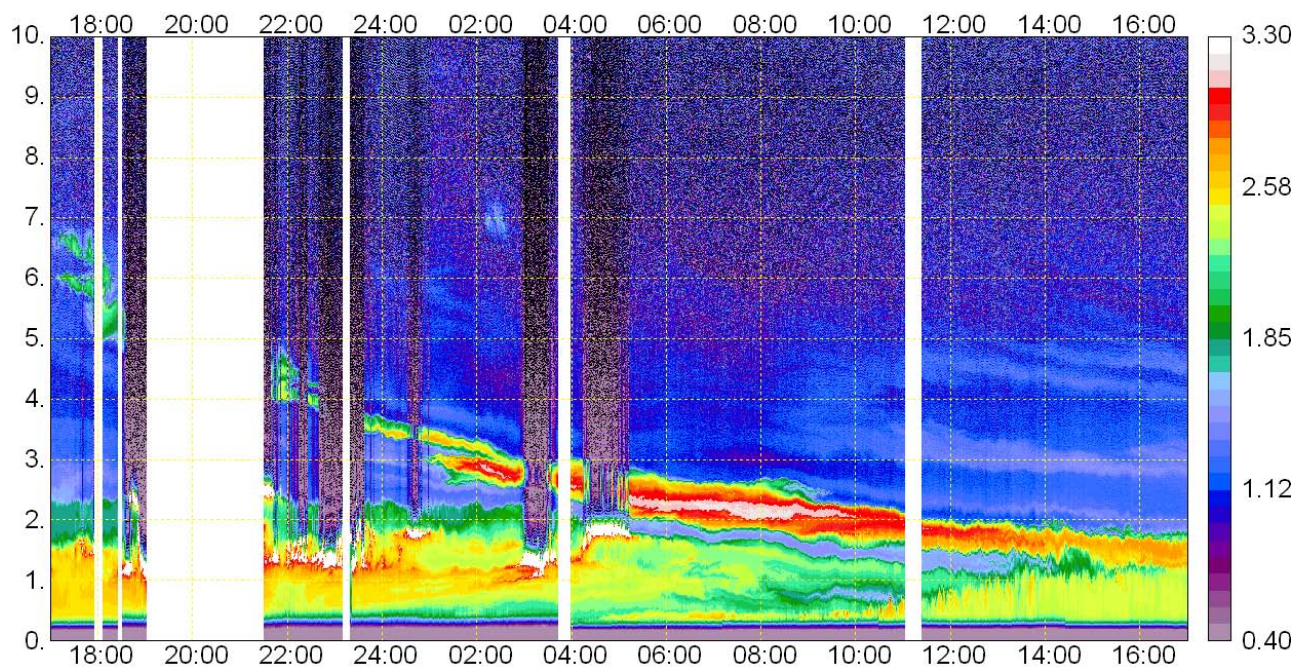

Fig. 1. Logarithm of range-corrected signal of MULIS at $\lambda=1064 \mathrm{~nm}$ over Maisach from 16 April 2010 17:00 UTC to 17 April 2010 17:00 UTC and from 0 to $10 \mathrm{~km}$ above ground; white areas denote periods without measurements.

to $41 \%$ at 00:00 UTC and 12:00 UTC over Oberschleißheim (approx. $22 \mathrm{~km}$ east of Maisach, $11 \mathrm{~km}$ north of Munich), indicating that the particles in the observed layer were dry.

\section{Retrieval of mass concentration from lidar}

This section describes the lidar systems, the forward simulation methods, and the lidar inversion approach, which we use for the retrieval of mass concentrations. The retrieval is applied to lidar measurements of the volcanic ash layer over Maisach at about 02:00 UTC on 17 April 2010.

\subsection{Lidar systems}

We performed range-resolved measurements of aerosol properties with two lidar systems: MULIS (multi-wavelength lidar system, e.g., Freudenthaler et al., 2009) and POLIS (portable lidar system, e.g., Groß et al., 2008). MULIS is a Raman- and depolarization-lidar including channels for elastic backscattering at $355 \mathrm{~nm}, 532 \mathrm{~nm}$, and $1064 \mathrm{~nm}$, and corresponding Raman channels for the determination of the extinction coefficient at $355 \mathrm{~nm}$ and $532 \mathrm{~nm}$. The linear depolarization ratio of particles is derived at $532 \mathrm{~nm}$. POLIS is a small low-power two-channel lidar for Raman or depolarization measurements at $355 \mathrm{~nm}$. As a consequence, combining the measurements from both lidars provides depolarization ratios at two wavelengths. The optical design of both lidars is optimized for measurements in the troposphere, i.e., MULIS provides data above $200 \mathrm{~m}$ to $400 \mathrm{~m}$ depending on field stop adjustments, POLIS above approximately $70 \mathrm{~m}$. Observations were made at Maisach $\left(48.209^{\circ} \mathrm{N}, 11.257^{\circ} \mathrm{E}\right.$, 515 m a.s.l.).

\subsection{Modeling of optical properties of spheroids}

For the inversion of lidar data we assume that ash particles are spheroids. Spheroids originate from rotation of ellipses about one of their axes. Rotation about the minor axis creates an oblate spheroid, whereas rotation about the major axis results in a prolate spheroid. One parameter, the aspect ratio $\epsilon^{\prime}$, is sufficient for the characterization of the shape of an oblate or a prolate spheroid. The aspect ratio $\epsilon^{\prime}$ is defined as the ratio of the longest to the shortest axis of the spheroid, which implies that $\epsilon^{\prime}$ is always equal or larger than 1. Spheroids with $\epsilon^{\prime}=1$ are spheres.

Throughout this paper, the radius $r$ of particles is specified by the cross-section-equivalent radius $r_{\mathrm{c}}$,

$r_{\mathrm{c}}=\sqrt{\frac{C_{\mathrm{geo}}}{\pi}}$

$C_{\text {geo }}$ is the orientation-averaged geometric cross sectional area of a particle. We use $r=r_{\mathrm{c}}$ as the parameter for the particle size because, for particles larger than the wavelength, their cross section is more relevant for the extinction of light than their volume. Note, that the volume-equivalent radius $r_{\mathrm{v}}$ of a particle with volume $V$

$r_{\mathrm{v}}=\sqrt[3]{\frac{3 V}{4 \pi}}$

can only be calculated from $r_{\mathrm{c}}$, if the radius conversion factor $\xi_{\mathrm{vc}}$ is known:

$\xi_{\mathrm{vc}}=\frac{r_{\mathrm{v}}}{r_{\mathrm{c}}}=\sqrt[3]{\frac{3 \sqrt{\pi}}{4}} \frac{\sqrt[3]{V}}{\sqrt{C_{\mathrm{geo}}}}$

In case of spheres $\xi_{\mathrm{vc}}$ is equal to 1 and it decreases with increasing particle non-sphericity. The radius conversion factor $\xi_{\mathrm{vc}}$ depends only on the shape of a particle, which means 
that isotropic scaling of a particle does not change $\xi_{\mathrm{vc}}$. For spheroids, analytical equations for $\xi_{\mathrm{vc}}$ are available (e.g., in the code from Mishchenko and Travis, 1998).

As we assume non-spherical particles in the inversion, Mie theory cannot be applied. The computation of optical properties of non-spherical particles, however, is very demanding with respect to computational time compared to the Mie theory. To facilitate fast simulations of optical properties of aerosol ensembles, we store the optical properties of a large number of single randomly-oriented spheroids in a database. For each particle in the database all relevant optical parameters are stored: The extinction efficiency $q_{\mathrm{ext}}=C_{\mathrm{ext}} /\left(\pi r_{\mathrm{c}}^{2}\right)$, the scattering efficiency $q_{\mathrm{sca}}=C_{\mathrm{sca}} /\left(\pi r_{\mathrm{c}}^{2}\right)$, and six elements $\left(F_{i j}\right)$ of the scattering matrix $\mathbf{F}(\theta)$, which depend on the scattering angle $\theta$, i.e., the angle between incident and scattering direction. The scattering matrix $\mathbf{F}(\theta)$ is stored in terms of expansion coefficients, allowing one to determine $\mathbf{F}(\theta)$ at any scattering angle $\theta$ (Mishchenko and Travis, 1998). The properties of spheroids are stored on a grid of different particle size parameters $x=2 \pi r / \lambda$, refractive indices $m=m_{\mathrm{r}}+m_{\mathrm{i}} i$, and aspect ratios $\epsilon^{\prime}$. Table 1 shows the grid points of the scattering database. For the calculation of optical properties of single spheroids the extended-precision version of the T-matrix code from Mishchenko and Travis (1998) is used. The size parameter $x$ that can be handled by the T-matrix code has, for numerical reasons, an upper limit, which depends on $\epsilon^{\prime}$ and $m$ (see Table 1, or Wiegner et al. (2009) for more details). For parameter ranges that are not covered by the T-matrix code, a combination of the geometric optics codes from Macke and Mishchenko (1996) and from Yang and Liou (1997) is used: The extinction efficiency $q_{\text {ext }}$ and scattering efficiency $q_{\mathrm{sca}}$ are taken from Yang's code because they consider edge effects for the calculation of $q_{\text {ext }}$ and $q_{\text {sca }}$. The scattering matrix $\mathbf{F}(\theta)$ is taken from Macke's code because comparisons in the overlap region of the numerically exact T-matrix code and both geometric optics codes showed better accuracy in backscatter direction for this code. From the geometric optics code no expansion coefficients are available, thus we store $\mathbf{F}(\theta)$ for a grid of 571 scattering angles $\theta$.

The extinction coefficient $\alpha$ for given wavelength $\lambda$, particle shape, and refractive index $m$ can be calculated by

$\alpha=\int_{r_{\min }}^{r_{\max }} \pi r^{2} q_{\mathrm{ext}}(r) n(r) d r$.

$n(r)=d N / d r$ is the particle number density per radius interval. As mentioned above, we use $r=r_{\mathrm{c}}$. The range from $r_{\text {min }}$ to $r_{\max }$ (integration limits omitted hereafter) should cover all relevant particle sizes. Analogously to $\alpha$, the backscatter coefficient $\beta$ is

$\beta=\int \pi r^{2} q_{\mathrm{sca}}(r) \frac{F_{11}\left(r, 180^{\circ}\right)}{4 \pi} n(r) d r$.

$F_{11}$ is the (1,1)-element of the scattering matrix $\mathbf{F}$. It is also known as the phase function and is normalized such that its
Table 1. Grid points of parameters in spheroid scattering database.

\begin{tabular}{lll}
\hline parameter & range & steps \\
\hline shapes & prolate and oblate spheroids & \\
aspect ratio $\epsilon^{\prime}$ & $1.2-3.0$ & +0.2 \\
& $3.0-5.0$ & +0.4 \\
real refr. index $m_{\mathrm{r}}$ & $1.28-1.68$ & +0.04 \\
& $1.68-2.00$ & +0.08 \\
imag. refr. index $m_{\mathrm{i}}$ & 0.0 and 0.0005375 & \\
& $0.001075-0.1376$ & $\times \sqrt{2}$ \\
size parameter $x$ of T-matrix method & \\
& $0.001-(10 \ldots 118)$ & \\
& max. depends on $\epsilon^{\prime}$ and $m$ & \\
size parameter $x$ of geometric optics approach & \\
& $10-2000$ & $\times 1.05$ \\
\hline
\end{tabular}

integral over all scattering directions is $4 \pi$. The linear depolarization ratio $\delta_{1}$ of aerosol particles can be calculated by

$\delta_{1}=\frac{\int \pi r^{2} q_{\mathrm{sca}}(r)\left(F_{11}\left(r, 180^{\circ}\right)-F_{22}\left(r, 180^{\circ}\right)\right) n(r) d r}{\int \pi r^{2} q_{\mathrm{sca}}(r)\left(F_{11}\left(r, 180^{\circ}\right)+F_{22}\left(r, 180^{\circ}\right)\right) n(r) d r}$.

$F_{22}$ is the $(2,2)$-element of the scattering matrix $\mathbf{F} . \alpha_{\lambda}, \beta_{\lambda}$, and $\delta_{1, \lambda}$ denote the optical properties at wavelength $\lambda$ in $\mathrm{nm}$.

The optical properties for a given refractive index $m$, if it is not included as a grid point in the single particle database (Table 1), are calculated assuming mixtures of particles with $m$ at the nearest grid points in the database; the relative frequencies of particles are selected such that the weighted mean $m$ matches the given $m$. The relative frequencies of the aspect ratios $\epsilon^{\prime}$ available in the database are calculated from the analytical aspect ratio distributions (Eq. 16), considering the step width of the $\epsilon^{\prime}$-grid (Table 1). Optical properties of ensembles consisting of particles of different shape and refractive index are calculated by adding the size-integrated extensive properties (Eq. 4, Eq. 5, or numerator and denominator of Eq. 6) of each particle shape and refractive index.

The mass concentration $M$ is calculated by

$M=\frac{4 \pi}{3} \rho \overline{\xi_{\mathrm{vc}}^{3}} \int r^{3} n(r) d r$.

$\rho$ is the mass density of the aerosol particles, and the cube of the shape-dependent radius conversion factor $\overline{\xi_{\mathrm{vc}}^{3}}$ (Eq. 3) is averaged over all particle shapes in the ensemble, assuming that particle shape is size-independent. For the mass density $\rho$ of the ash particles we assume $2.6 \mathrm{~g} \mathrm{~cm}^{-3}$, which is the same as the density of mineral dust given in the OPAC database (Hess et al., 1998); to our knowledge, there are no indications that the density of volcanic ash particles is systematically different from the density of mineral dust particles. For the conversion of extinction coefficients to mass concentrations we use the mass-extinction conversion factor $\eta$

$\eta=\frac{M}{\alpha}$. 
Note, that $\eta$ is the inverse of the mass extinction coefficient. We calculate the effective radius $r_{\text {eff }}$ of an ensemble as

$r_{\mathrm{eff}}=\frac{\int r^{3} n(r) d r}{\int r^{2} n(r) d r}$

$r_{\text {eff }}$ is defined in terms of cross-section-equivalent radii because we use $r=r_{\mathrm{c}}$ throughout this paper. The term $\left(\overline{\xi_{\mathrm{vc}}^{3}} r_{\mathrm{eff}}\right)$ is equal to an alternative definition $3 V / 4 A$ for the effective radius, where $V$ is the volume density and $A$ the projected area density (e.g., Schumann et al., 2010a). Using the mean extinction efficiency $\overline{q_{\mathrm{ext}}}$, which is given by

$\overline{q_{\mathrm{ext}}}=\frac{\int q_{\mathrm{ext}}(r) r^{2} n(r) d r}{\int r^{2} n(r) d r}$,

we can derive a relation between $\eta$ and $r_{\mathrm{eff}}$,

$\eta=\frac{4}{3} \frac{\rho \overline{\xi_{\mathrm{vc}}^{3}}}{\overline{q_{\mathrm{ext}}}} r_{\mathrm{eff}}$.

\subsection{Inversion approach}

Modeling of optical properties of aerosol ensembles with known microphysical properties is a forward problem. Forward problems have unique solutions and are solved on the basis of physical theories, e.g., the T-matrix method for scattering of light by spheroids. Conversely, in case of inverse problems, one tries to find physical properties of a system by using information from observations of the system. In the case under consideration, only a limited number of optical aerosol properties is available to find the microphysical properties of the observed aerosol. As, in general, many aerosol ensembles exist that are compatible with the measurements, the solution of the inverse problem is a distribution of compatible aerosol ensembles.

The approach for the inversion of lidar data that we use in this paper is an example for Bayesian inference (Mosegaard and Tarantola, 2002; Tarantola, 2006). To our knowledge, an Bayesian approach has been used for inversion of lidar data only by Herman et al. (2008). We retrieve microphysical aerosol properties by repeated forward calculations of model aerosol ensembles with varying microphysical properties (see below) and by comparison of their optical properties with the optical properties from the lidar measurements (Fig. 2). In the first step, only intensive properties are retrieved, thus we consider an aerosol ensemble as compatible with the lidar measurements, if all simulated (superscript $s$ ) linear depolarization ratios and ratios between extensive properties are within the uncertainty ranges from the lidar measurements (superscript $m$ ), i.e.,

$y^{m}\left(1-\Delta_{y}\right)<y^{s}<y^{m}\left(1+\Delta_{y}\right)$

for $y \in\left\{\delta_{1,355}, \delta_{1,532}\right\}$, and

$\frac{y_{1}^{m}\left(1-\Delta_{y 1}\right)}{y_{2}^{m}\left(1+\Delta_{y 2}\right)}<\frac{y_{1}^{s}}{y_{2}^{s}}<\frac{y_{1}^{m}\left(1+\Delta_{y 1}\right)}{y_{2}^{m}\left(1-\Delta_{y 2}\right)}$

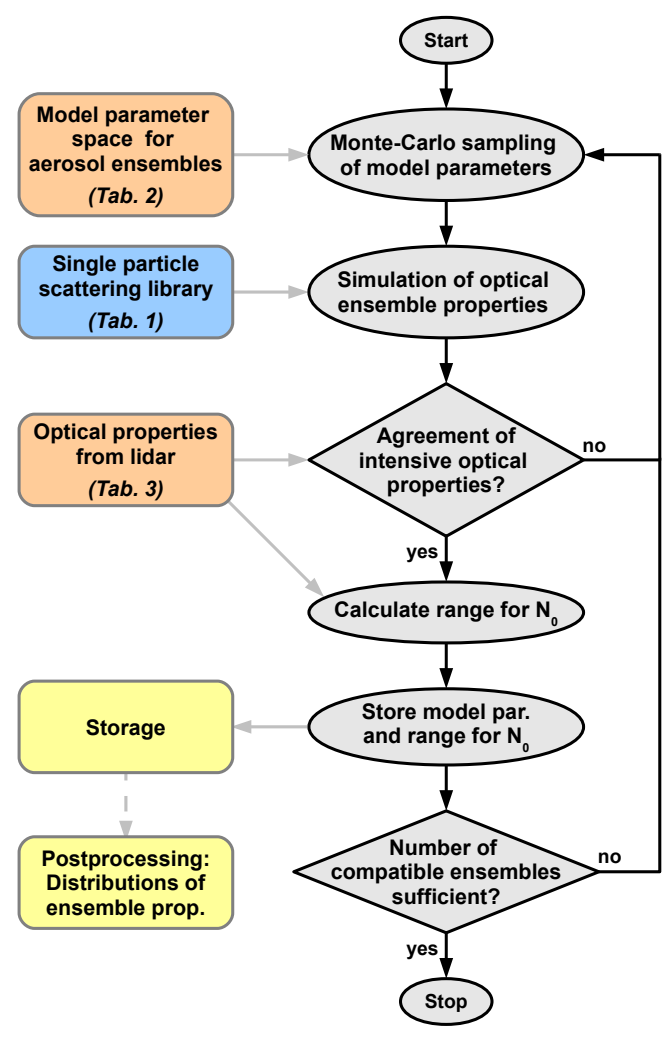

Fig. 2. Flow chart of retrieval from lidar measurements; colored boxes and grey arrows denote input and output.

for $y_{1}, y_{2} \in\left\{\alpha_{355}, \alpha_{532}, \beta_{355}, \beta_{532}, \beta_{1064}\right\} . \Delta_{y}$ denote the relative uncertainties of the measured parameters $y$. In the second step, for each compatible aerosol ensemble the range of particle number densities $N_{0}=\int n(r) d r$ from $N_{0, \min }$ to $N_{0, \max }$ is calculated, for which simulated extensive properties are within the uncertainty ranges from lidar, i.e.,

$y^{m}\left(1-\Delta_{y}\right)<y^{s}<y^{m}\left(1+\Delta_{y}\right)$

for $y \in\left\{\alpha_{355}, \alpha_{532}, \beta_{355}, \beta_{532}, \beta_{1064}\right\}$. For statistical analyses, $N_{0}$ in the range from $N_{0, \text { min }}$ to $N_{0, \text { max }}$ is assumed to be equiprobable. The result of the inversion is a distribution of compatible aerosol ensembles together with their compatible ranges for $N_{0}$. Any property of interest, for example the mass-extinction conversion factor $\eta$, can be derived from this distribution of ensembles. As a consequence, the solution for the property of interest is also a distribution. In this paper, the medians of the distributions, i.e. the values separating the distributions into two equiprobable parts, are given. Ranges including $95 \%$ of the solutions are denoted as $(\min \cdot \max )$.

Model aerosol ensembles are specified by parameters for their microphysical properties. In this paper, the size distribution $n(r)$ of an ensemble is a mono-modal log-normal distribution

$n(r)=\frac{d N}{d r}=\frac{N_{0}}{\sqrt{2 \pi} \ln \sigma r} \exp \left[-\frac{1}{2}\left(\frac{\ln r-\ln r_{0}}{\ln \sigma}\right)^{2}\right]$ 
Table 2. Ranges of microphysical parameters for lidar inversion.

\begin{tabular}{lrr}
\hline parameter & $\begin{array}{r}\text { range } \\
\text { lower bound. }\end{array}$ & upper bound. \\
\hline$r_{0}$ (log. sampling) & $0.01 \mu \mathrm{m}$ & $10 \mu \mathrm{m}$ \\
$\sigma$ & 1.2 & 4.0 \\
$m_{\mathrm{r}}$ & 1.28 & 2.00 \\
$m_{\mathrm{i}}$ & 0.0 & 0.1 \\
$\zeta$ & 0 & 1 \\
$\mu_{p}, \mu_{o}$ & -0.6 & 0.6 \\
$\sigma_{p}, \sigma_{o}$ & 0.5 & 1.5 \\
\hline
\end{tabular}

which is specified by the modal radius $r_{0}$ and the width $\sigma$ of the mode. As only intensive properties are retrieved in the first step, $N_{0}$ becomes only relevant in the second step, where extensive properties are provided. The size of a nonspherical particle is specified by the cross-section-equivalent radius $r_{\mathrm{c}}$. The model aerosol ensembles cover a range from $r_{\min }=20 \mathrm{~nm}$ to $r_{\max }=20 \mu \mathrm{m}$. The wavelength-independent refractive index is given by a real part $m_{\mathrm{r}}$ and an imaginary part $m_{\mathrm{i}}$. The ensembles consist of spheroids, and the shape distribution is specified by five parameters: Parameter $\zeta$ describes the relative frequency of prolate spheroids; this implies the frequency of oblate spheroids to be $(1-\zeta) . \mu_{p}$ and $\sigma_{p}$ specify the aspect ratio distribution $f_{p}\left(\epsilon^{\prime}\right)$ (adapted from Kandler et al., 2007) of prolate spheroids:

$f_{p}\left(\epsilon^{\prime}\right)=\frac{1}{\sqrt{2 \pi} \sigma_{p}\left(\epsilon^{\prime}-1\right)} \exp \left[-\frac{1}{2}\left(\frac{\ln \left(\epsilon^{\prime}-1\right)-\mu_{p}}{\sigma_{p}}\right)^{2}\right]$

$\mu_{o}$ and $\sigma_{o}$ are the corresponding parameters for the aspect ratio distribution $f_{o}\left(\epsilon^{\prime}\right)$ of oblate spheroids, which is independent of $f_{p}\left(\epsilon^{\prime}\right)$. We do not allow narrow aspect ratio distributions $\left(\sigma_{p / o}<0.5\right)$ because wide aspect ratio distributions are necessary for realistic simulations of optical properties (see e.g., Mishchenko et al., 1997). The refractive index and the particle shape are size-independent.

For the inversion, the parameters of the model aerosol ensembles are randomly sampled within wide ranges (see Table 2) using a Monte Carlo approach with a Mersenne Twister pseudo random number generator (MT19937). The sampling is continued until a sufficient number of compatible aerosol ensembles is found. Whereas for a first estimate of the microphysical properties 100 ensembles may be enough, for smooth distributions of retrieved parameters significantly more ensembles are necessary. On one core of an Intel Xeon 5130 processor, about 5000 ensembles per second are modeled, but the computational speed of the retrieval also depends on the probability to find compatible ensembles. For the wide ranges given in Table 2 the ratio of compatible ensembles to all ensembles is only about 1:200 000. As a consequence, if all four cores of the processor are used, about 360 compatible ensembles per hour are found.
Table 3. Lidar-derived optical properties of volcanic ash plume at 02:00 UTC on 17 April 2010; uncertainty is the sum of systematic and stochastic uncertainty.

\begin{tabular}{lrr}
\hline parameter & value & relative uncertainty \\
\hline$\alpha_{355}$ & $0.348 \mathrm{~km}^{-1}$ & $\pm 7.4 \%$ \\
$\alpha_{532}$ & $0.371 \mathrm{~km}^{-1}$ & $\pm 11.1 \%$ \\
$\beta_{355}$ & $0.00604 \mathrm{~km}^{-1} \mathrm{sr}^{-1}$ & $\pm 5.3 \%$ \\
$\beta_{532}$ & $0.00755 \mathrm{~km}^{-1} \mathrm{sr}^{-1}$ & $\pm 4.1 \%$ \\
$\beta_{1064}$ & $0.00583 \mathrm{~km}^{-1} \mathrm{sr}^{-1}$ & $\pm 16 \%$ \\
$\delta_{1,355}$ & 0.355 & $\pm 4.4 \%$ \\
$\delta_{1,532}$ & 0.373 & $\pm 2.0 \%$ \\
\hline
\end{tabular}

\subsection{Application to measurements of 17 April}

We apply this inversion approach to optical data from the lidar measurements of volcanic ash in about $3 \mathrm{~km}$ over Maisach at around 02:00 UTC on 17 April 2010 (see Fig. 1). Vertical profiles of the extinction coefficient $\alpha$ and backscatter coefficient $\beta$ of the aerosol particles at $\lambda=355 \mathrm{~nm}$ and $532 \mathrm{~nm}$ were derived using the Raman approach (Ansmann et al., 1992). Vertical profiles of the other optical parameters, i.e. the linear depolarization ratio $\delta_{1}$ at $\lambda=355 \mathrm{~nm}$ and $532 \mathrm{~nm}$, and $\beta$ at $\lambda=1064 \mathrm{~nm}$, were derived using the approaches described by Freudenthaler et al. (2009) and Fernald (1984), respectively. To increase the signal-to-noise ratio, temporal averages from 1:30 UTC to 2:40 UTC were considered. As input for the inversion, we use optical parameters of the ash particles averaged over a layer of $400 \mathrm{~m}$ vertical extent, centered at the maximum of the backscatter coefficient $\beta$ at $2.88 \mathrm{~km}$ above ground. The optical data and their uncertainties are summarized in Table 3 . The uncertainty is given here as the sum of the stochastic and the systematic uncertainty (Groß et al., 2010). As mentioned above, Table 2 shows the ranges of microphysical parameters for the aerosol ensembles that are considered for the Monte Carlo sampling in the inversion. Thus, the data in Table 2 and 3 serve as input for the inversion.

The most relevant intensive property from the inversion in the context of this paper is the mass-extinction conversion factor $\eta$. The frequency distribution of $\eta$ for the ash plume at $\lambda=532 \mathrm{~nm}$ is shown in Fig. 3. 100000 compatible aerosol ensembles are evaluated. We find a median mass-extinction conversion factor $\eta=1.45 \mathrm{~g} \mathrm{~m}^{-2}$ (green line). $95 \%$ of the compatible ensembles are in the range $\left(0.87 \cdot 2.32 \mathrm{~g} \mathrm{~m}^{-2}\right)$ (red lines). We find a mass concentration $M=0.54 \mathrm{mg} \mathrm{m}^{-3}$ $\left(0.33 \cdot 0.87 \mathrm{mg} \mathrm{m}^{-3}\right)$ for around 2:00 UTC, when the extinction coefficient $\alpha$ at $\lambda=532 \mathrm{~nm}$ was $0.371 \mathrm{~km}^{-1}$.

According to Eq. 11, the mass-extinction conversion factor $\eta$ depends on the cross-section-equivalent effective radius $r_{\text {eff }}$ of the ash particles. To illustrate this relationship, Fig. 4 shows a scatter plot of $\eta$ over $r_{\text {eff }}$ of the solutions of the inversion. $\eta$ and $r_{\text {eff }}$ are highly 


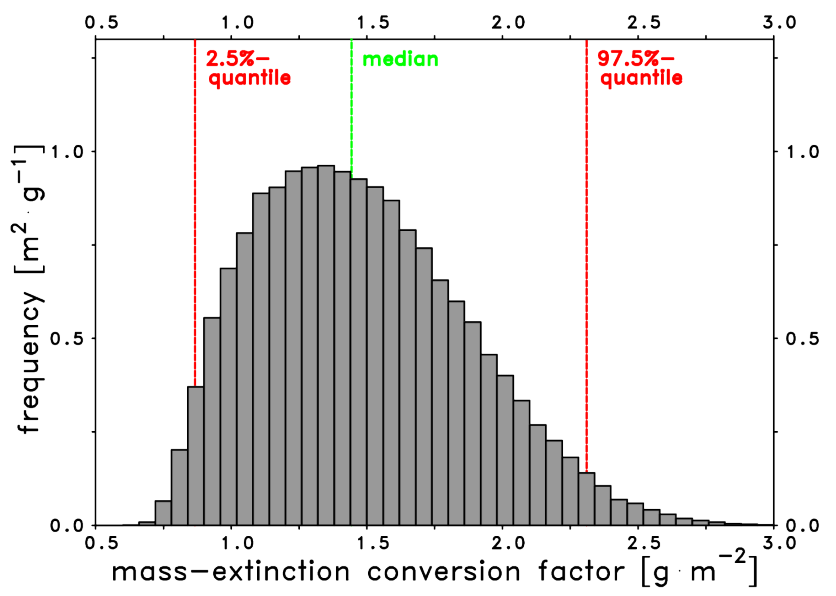

Fig. 3. Frequency distribution of solutions of retrieval from lidar measurements for mass-extinction conversion factor $\eta$ at $\lambda=532 \mathrm{~nm}$ of volcanic ash over Maisach on 17 April 2010 at 02:00 UTC.

correlated, demonstrating that $r_{\text {eff }}$ is the most uncertain parameter for the determination of $\eta$. The relationship between $\eta$ at $\lambda=532 \mathrm{~nm}$ and $r_{\text {eff }}$ can be well approximated by the linear function $\eta=1.346 \mathrm{~g} \mathrm{~m}^{-2} \mu \mathrm{m}^{-1} r_{\text {eff }}$ $0.156 \mathrm{~g} \mathrm{~m}^{-2}$ (standard deviation $0.042 \mathrm{~g} \mathrm{~m}^{-2}$ ). From the lidar retrieval, we find a cross-section-equivalent effective radius $r_{\text {eff }}=1.19 \mu \mathrm{m}(0.76 \cdot 1.83 \mu \mathrm{m})$, a radius conversion factor $\overline{\xi_{\mathrm{vc}}^{3}}=0.87(0.82 \cdot 0.91)$, and an extinction efficiency $\overline{q_{\mathrm{ext}}}=2.48(2.37 \cdot 2.68)$ at $\lambda=532 \mathrm{~nm}$.

The lidar measurements suggest that there was no change of intensive properties of the ash particles from 02:00 to 08:00 UTC. We apply the intensive properties found for 02:00 UTC also at 08:00 UTC, when no Raman measurements were available. At that time, the maximum of the ashrelated extinction coefficient $\alpha$ with values around $0.75 \mathrm{~km}^{-1}$ (Fig. 5) was observed in about $2.2 \mathrm{~km}$, averaged over one hour and $80 \mathrm{~m}$ in the vertical. We find a mass concentration $M$ of $1.1 \mathrm{mg} \mathrm{m}^{-3}\left(0.65 \cdot 1.8 \mathrm{mg} \mathrm{m}^{-3}\right)$ for the maximum of the ash plume over Maisach. If we consider the optical depth of the ash layer $\tau=0.34$ at $\lambda=532 \mathrm{~nm}$ (vertical integral of $\alpha$ from $1.7 \mathrm{~km}$ to $2.7 \mathrm{~km}$ above ground), the ash load, i.e. the vertical integral of $M$, over Maisach was $0.5 \mathrm{~g} \mathrm{~m}^{-2}$ $\left(0.3 \cdot 0.8 \mathrm{~g} \mathrm{~m}^{-2}\right)$.

\subsection{Discussion of results from the lidar inversion}

As mentioned above, several assumptions were applied for the optical modeling of the aerosol ensembles in the context of the inversion, e.g., assumptions on spectral changes of the refractive index $m$, on particle shape, and on the form of the size distributions. These assumptions can potentially bias the results of the inversion. E.g., the retrieved real part of the refractive index $m_{\mathrm{r}}$ is $1.43(1.35 \cdot 1.50)$, which is smaller than the refractive index typically measured for volcanic ash; for example, Patterson et al. (1983) estimate $m_{\mathrm{r}}$ for ash from

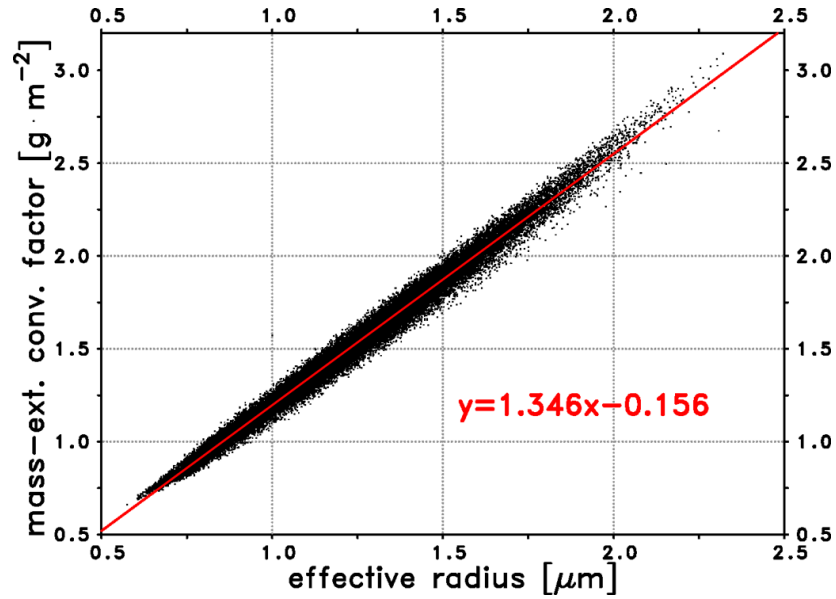

Fig. 4. Solutions of retrieval from lidar measurements for massextinction conversion factor $\eta$ at $\lambda=532 \mathrm{~nm}$ and cross-sectionequivalent effective radius $r_{\mathrm{eff}}$; red: least squares fit of a straight line.

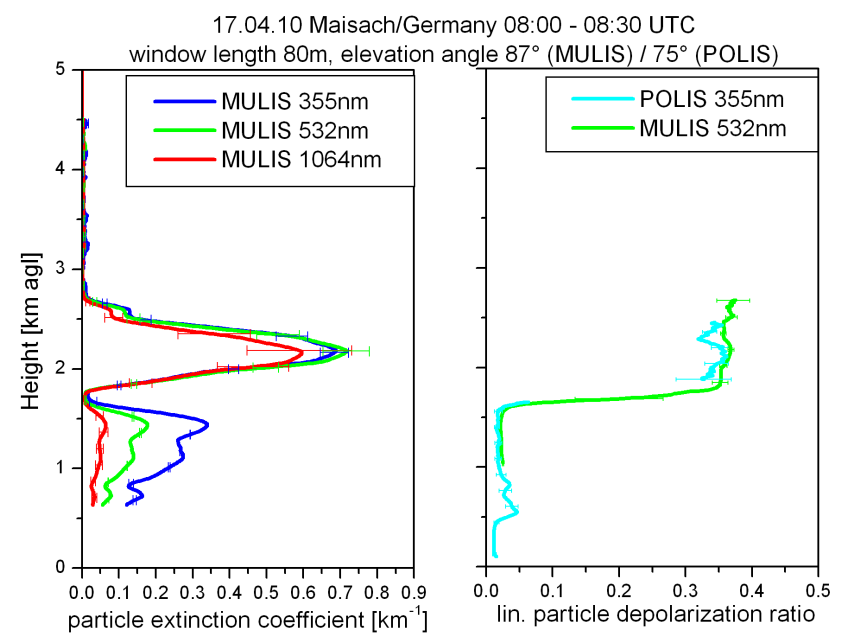

Fig. 5. Vertical profile of aerosol extinction coefficients $\alpha$ and linear depolarization ratios $\delta_{1}$ averaged from 08:00 UTC to 08:30 UTC on 17 April 2010; boundary layer from ground to $1.7 \mathrm{~km}$, volcanic ash from $1.7 \mathrm{~km}$ to $2.7 \mathrm{~km}$; error bars indicate systematic error.

the El Chichón volcano to be 1.53. Based on forward calculations of irregularly-shaped particles (not shown), we expect that the simplifying assumptions about the particle shape may lead to an underestimation of $m_{\mathrm{r}}$ by the lidar retrieval.

Another issue is the physical limitation of the methodology, in particular with respect to the sensitivity for large particles. To investigate that, Fig. 6 shows differential backscattering cross sections per particle volume for prolate spheroids with two aspect ratios, i.e. $\epsilon^{\prime}=1.8$ and $\epsilon^{\prime}=2$.4. The figure is for $\lambda=1064 \mathrm{~nm}$, which is the maximum wavelength of our lidars, and a refractive index of $m=1.48+0.0043 i$, which is within the range of the retrieved refractive indices. The intensity backscattered by a particle is proportional to its 


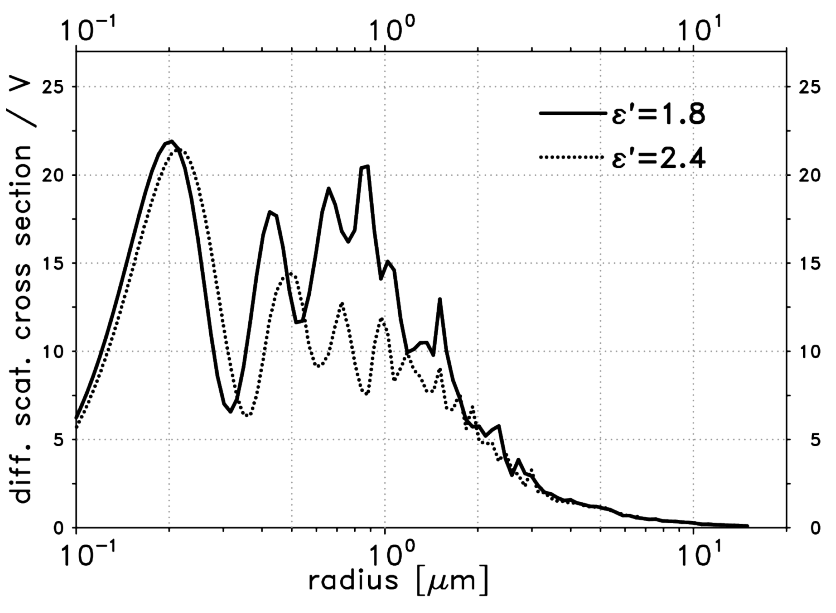

Fig. 6. Differential backscattering cross section per particle volume $\left(C_{\text {sca }} \times F_{11}\left(180^{\circ}\right) / V\right.$, arbitrary scale) over cross-sectionequivalent radius $r_{\mathrm{c}}$ of prolate spheroids with different aspect ratios $\epsilon^{\prime} ; \lambda=1064 \mathrm{~nm} ; m=1.48+0.0043 i$.

differential backscattering cross section. For particles with radii $r>1 \mu \mathrm{m}$, the backscattered intensity per particle volume decreases with size, which is immediately clear from Fig. 6. This is consistent with findings for spherical particles, e.g., from Müller and Quenzel (1985). For particles with $r=3 \mu \mathrm{m}$, the backscattered intensity per particle volume is only $15 \%-25 \%$ of the corresponding value for particles with $r=1 \mu \mathrm{m}$. This implies that, if particles with $r \gtrsim 3 \mu \mathrm{m}$ significantly contribute to the total volume, the retrieved $M$ could be underestimated. Indeed, if we extend the above-described aerosol model by a second mode, larger mass-extinction conversion factors $\eta$ are compatible with the measurements: For two-modal ensembles (both modes having independent parameters as given in Table 2 and $0.001<N_{0,1} / N_{0,2}<1000$ ) we find $\eta=1.5 \mathrm{~g} \mathrm{~m}^{-2}\left(0.9 \cdot 3.4 \mathrm{~g} \mathrm{~m}^{-2}\right)$ at $\lambda=532 \mathrm{~nm}$.

Our retrieved mass-extinction conversion factor $\eta$ is in the same range as the estimate from Ansmann et al. (2010), which was $1.95 \mathrm{~g} \mathrm{~m}^{-2}$ for the younger ash plume over Leipzig, Germany, on 16 April 2010. They assumed that $\eta$ for mineral dust from OPAC (Hess et al., 1998) is applicable to volcanic ash. According to the correlation from Fig. 4, this $\eta$ corresponds to an effective radius of about $1.6 \mu \mathrm{m}$.

Though our retrieval of $\eta$ compares well with other estimates, uncertainty remains due to the insensitivity of the lidar signals for large particles. Thus, independent studies are desirable. For that we use information from sky radiance measurements in the aureole of the Sun, which are described in the following section.

\section{Consistency check}

The presence of micrometer- and super-micrometer-sized aerosol particles in the atmosphere causes a bright zone around the solar disc, which is known as the aureole of the Sun. The aureole is a result of diffraction of sunlight by the particles. The angular width of the main diffraction peak, which is around the forward scattering direction $\theta=0^{\circ}$, primarily depends on the ratio between particle size and wavelength (van de Hulst, 1981). The exploitation of sky radiances $L$ in the aureole to retrieve the size of aerosol particles has a long tradition, e.g., Thomalla and Quenzel (1982), Nakajima et al. (1983) or Dubovik et al. (2006). In this paper, we use the ratio of radiances at two scattering angles and $\lambda=1020 \mathrm{~nm}$. The term "scattering angle" is used for the sake of brevity: it is meant as the angular difference between the direction of the Sun and the direction of observation in the principle plane (above the Sun). A benefit of the radiances in the aureole is that they are more sensitive to larger particles than the lidar signals, thus the presence of large particles can be investigated in more detail (see Sect. 4.4). Because of the relationship between particle size (in terms of $r_{\text {eff }}$ ) and the mass-extinction conversion factor $\eta$ (see Eq. 11, Fig. 4), sky radiances in the aureole can indirectly be used for an estimate of $\eta$ also.

The approach for our consistency check is independent from the lidar retrieval of the previous section. The basic idea for the consistency check is to calculate sky radiances for two scattering angles by means of a radiative transfer model, and to compare the modeled ratio to the ratio from the measurements. If they agree, we get a solution for $r_{\text {eff }}$ and $\eta$ of the ash particles that is consistent with the photometer data. The solutions are compared to the results from the lidar retrieval. We consider the vertical aerosol distribution from the lidar measurements and the uncertainty of the aerosol properties for the sky radiance simulations.

\subsection{Instrumentation and data}

An automatic CIMEL CE-318 Sun photometer is installed on the roof of the Meteorological Institute of the LudwigMaximilians-Universität in downtown Munich $\left(48.148^{\circ} \mathrm{N}\right.$, $11.573^{\circ} \mathrm{E}, 539 \mathrm{~m}$ a.s.1.). It is part of AERONET, which is a global network of Sun photometers for the characterization of aerosols (Holben et al., 1998). The photometer measures the direct solar irradiances at several wavelengths which allows one to determine the spectral optical depth of aerosols. Furthermore, CIMEL measures sky radiances $L$ at several wavelengths in the almucantar and the principle plane, i.e. a circle around the local zenith containing the Sun and a line through the local zenith and the Sun, respectively.

For the consistency check we consider the CIMEL principle-plane measurement of sky radiances from 17 April 2010 at 08:22 UTC. The solar zenith angle was $51.8^{\circ}$. For our investigation we calculate the ratio of $L$ at scattering angles of $4^{\circ}$ and $3^{\circ}$, i.e., $L\left(4^{\circ}\right) / L\left(3^{\circ}\right)$, at $\lambda=1020 \mathrm{~nm}$. Henceforward this ratio is referred to as $\Lambda$. The largest wavelength of the CIMEL is best suited for our purposes because it is less affected by the boundary layer 
Table 4. Aerosol parameters considered for sky radiance simulations of CIMEL measurement on 17 April 2010 at 08:22 UTC in Munich; $\lambda=1020 \mathrm{~nm}$; no aerosol in heights $>2.7 \mathrm{~km}$; size distributions are mono-modal and bi-modal log-normal distributions.

\begin{tabular}{lll}
\hline parameter & bound. layer aerosol & volcanic ash \\
\hline shape & spheres & shapes A, B, C from Fig. 7; spheres (for comparison) \\
real refr. index $m_{\mathrm{r}}$ & $1.35,1.65$ & $1.5,1.6$ \\
imag. refr. index $m_{\mathrm{i}}$ & $0.0,0.05$ & $0,0.01$ \\
effective radius $r_{\mathrm{eff}}$ & $0.11,0.26 \mu \mathrm{m}$ & $0.8,1.0,1.2,1.5,2.0,3.0 \mu \mathrm{m}$ \\
form of size distr. & mono-modal: $\sigma=1.6$ & $\# 1$ mono-modal: $\sigma=1.8$ \\
$\quad$ (SD) & mono-modal: $\sigma=2.4$ & $\# 2$ mono-modal: $\sigma=2.4$ \\
& & $\# 3$ bi-modal: $\sigma_{1 / 2}=1.8, r_{0,1} / r_{0,2}=0.25, N_{0,1} / N_{0,2}=16$ \\
& & $\# 4$ bi-modal: $\sigma_{1 / 2}=1.8, r_{0,1} / r_{0,2}=0.10, N_{0,1} / N_{0,2}=100$ \\
\hline vertical extent & $0.0-1.7 \mathrm{~km}$ & $1.7-2.7 \mathrm{~km}$ \\
optical depth & $0.056,0.084$ & $0.324,0.216$ \\
\hline
\end{tabular}

aerosol than shorter wavelengths. This is obvious from the $1064 \mathrm{~nm}$ extinction coefficient profile as shown in Fig. 5.

Next to the CIMEL, a JenOptik CHM15kx ceilometer is continuously monitoring the vertical aerosol distribution at $\lambda=1064 \mathrm{~nm}$ over Munich (Wiegner, 2010). Measurements of the ceilometer (not shown) and MULIS (Fig. 1) reveal very similar vertical and temporal distributions of the aerosol layers over both sites in the morning of 17 April 2010. Thus, we assume that the same ash type, in terms of intensive prop-

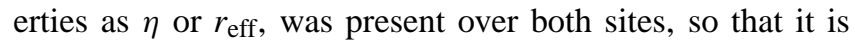
justified to use sky radiance measurements in Munich for a consistency check of the retrieval from lidar measurements in Maisach.

\subsection{Radiative transfer calculations}

For modeling sky radiances we used the software package libRadtran (Mayer and Kylling, 2005). The Monte Carlo code MYSTIC (Mayer, 2009) was used to solve the radiative transfer equation because it allows one to accurately calculate aureole even for strongly-peaked phase functions.

To perform the sky radiance simulations, the knowledge of the atmospheric parameters, in particular the characteristics of the aerosols as a function of height, is required. In this context, the pronounced two layer structure with the planetary boundary layer (below $1.7 \mathrm{~km}$ ) and the elevated ash layer (from $1.7 \mathrm{~km}$ to $2.7 \mathrm{~km}$ ) as known from MULIS measurements in Maisach around 8:00 UTC is considered (see Fig. 5). Above $2.7 \mathrm{~km}$, a pure Rayleigh atmosphere is assumed. For both aerosol layers we select different sets of intensive properties; they are summarized in Table 4.

For the characterization of the boundary layer we assume spherical particles because low linear depolarization ratios $\delta_{1}$ were derived from the lidar measurements. The values for the refractive index and the width of the size distributions cover the range of tropospheric aerosols typical for Munich. The effective radius $r_{\text {eff }}$ of the boundary layer aerosol particles was estimated from the wavelength dependence of the $\alpha$-profiles of the aerosols.
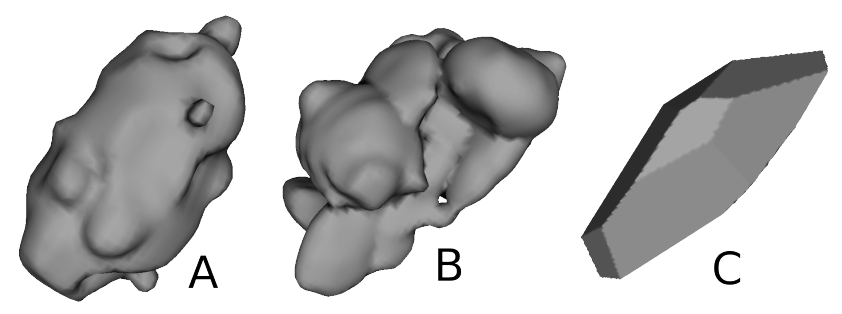

Fig. 7. Irregularly-shaped particles for sky radiance simulations.

To investigate the relevance of the shape of the ash particles for the sky radiances, spheres (as the most simple case) and irregular morphologies as shown in Fig. 7 are modeled. The morphologies include a prolate spheroid with surface deformations according to the Gardner series (Gardner, 1984) and aspect ratio $\epsilon^{\prime}=1.8$ (shape A), an aggregate particle (shape B), and a sharp-edged particle (shape C). For the creation of these model particles we use the volume modeling language Hyperfun (Valery et al., 1999). The single scattering properties are calculated using the discrete dipole approximation. For that we use the ADDA code (Yurkin et al., 2007) with the "filtered coupled dipole" option and 11 dipoles per wavelength. As computation time significantly increases with the size parameter $x$, we have to limit our calculations to $x \leq 20.8$, which corresponds to $r \leq 3.4 \mu \mathrm{m}$ at $\lambda=1020 \mathrm{~nm}$. Particles with $r>3.4 \mu \mathrm{m}$ are assumed to be spheroids (Dubovik et al., 2006). For the refractive index we consider a wide range, i.e. a real part $m_{\mathrm{r}}$ between 1.5 and 1.6 and an imaginary part $m_{\mathrm{i}}$ between 0 and 0.01 . These values are expected to cover the uncertainty about the refractive index of ash at $\lambda=1020 \mathrm{~nm}$ (e.g., Patterson et al., 1983). The size distributions of the ash layer particles are defined by their effective radius and their form. They include six crosssection-equivalent effective radii $r_{\text {eff }}$ and four forms (SD\#1SD\#4); they are shown for $r_{\text {eff }}=1 \mu \mathrm{m}$ as volume distributions $d V(r) / d \ln r$ in Fig. 8. The forms include a narrow monomodal distribution $(\sigma=1.8$; SD\#1), a wide mono-modal case $(\sigma=2.4$; SD\#2), and two bi-modal distributions (SD\#3 and 


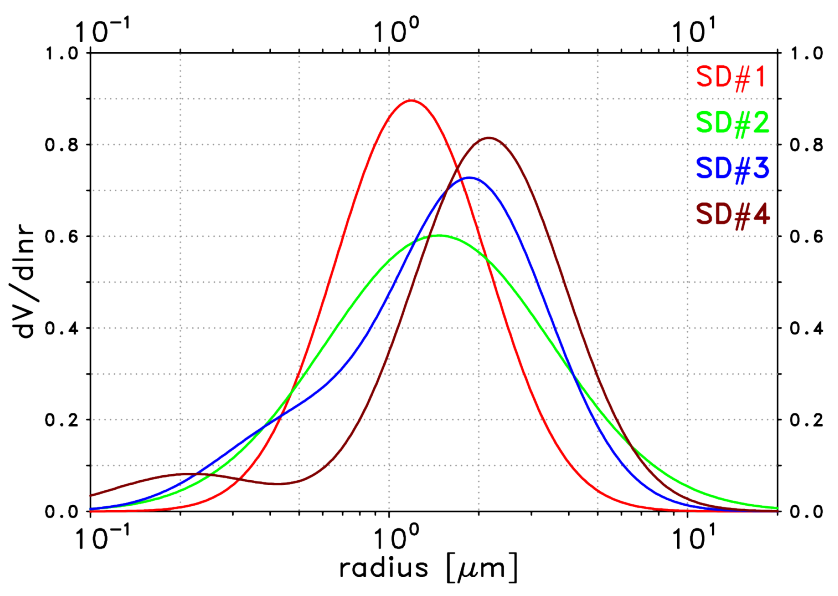

Fig. 8. Volume distribution (arbitrary scale) of different forms of size distribution (SD, Table 4), but same effective radius $r_{\mathrm{eff}}=1 \mu \mathrm{m}$.

SD\#4). Both modes in the bi-modal size distributions have equal cross-sectional area, but different volume. The modal radii $r_{0}$ of the size distributions follow from given effective radii and the forms of the size distribution. In total 24 size distributions for the ash are considered. These quite different forms of size distributions and $r_{\text {eff }}$ are expected to cover the range of realistic size distributions for ash particles. SD\#1 is considered as the lower limit with respect to the width of the size distribution because volcanic ash particles typically have a wide range of sizes (e.g., Mather et al., 2003; Schumann et al., 2010b). In all simulations, particles up to $r=40 \mu \mathrm{m}$ are accounted for. The single scattering properties of the aerosols are calculated as described above and serve as input for the MYSTIC calculations.

Finally, the vertical profile of the extinction coefficient $\alpha$ of the aerosols has to be defined. We do not apply the highresolution profiles from the lidar measurements (Fig. 5), but assume height-independent extinction coefficients in each of the two aerosol layers. The extinction coefficients of the aerosols are calculated from the optical depths and the vertical extents of the layers. From the lidar measurements at $1064 \mathrm{~nm}$ we find 0.07 for the optical depth of the lower layer and 0.27 for the ash layer. We assume an uncertainty of $20 \%$, and simulate one case with an optical depth of 0.056 for the lower layer and 0.324 for the ash layer and another case with 0.084 for the lower layer and 0.216 for the ash layer. It is worth mentioning that the aerosol optical depth from the lidar and the CIMEL radiometer agree quite well; they are 0.34 and 0.31 , respectively.

As a result, we perform radiative transfer calculations with a total of 12288 parameter-combinations to account for the uncertainty of the aerosol properties.

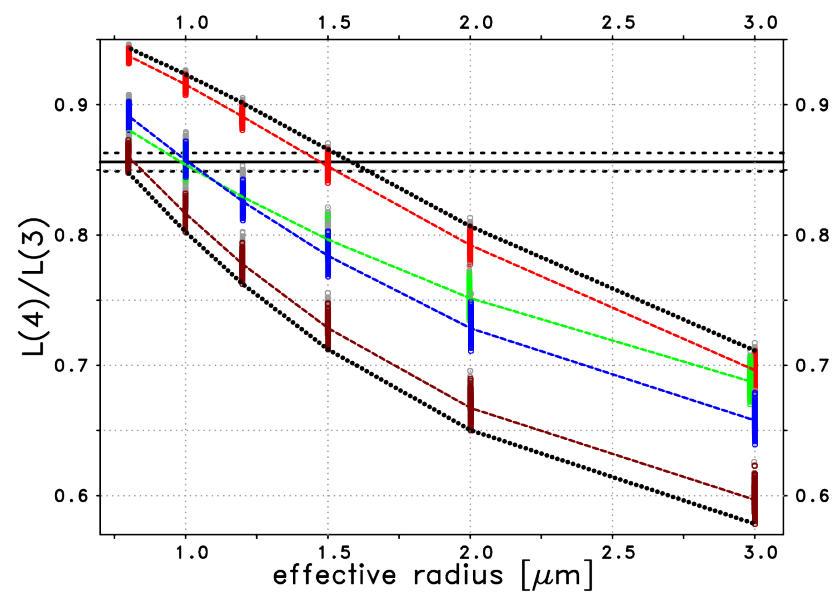

Fig. 9. Simulated ratios of aureole radiances $\Lambda=L\left(4^{\circ}\right) / L\left(3^{\circ}\right)$ at $\lambda=1020 \mathrm{~nm}$ over cross-section-equivalent effective radius $r_{\text {eff }}$ of ash particles; averages for different $r_{\text {eff }}$, but same SD are connected by dashed lines; red, green, blue, brown: non-spherical ash with SD\#1 to SD\#4; grey: spherical ash; black dotted: uncertainty range from simulations with non-spherical ash; horizontal lines: CIMEL measurement with uncertainty.

\subsection{Comparison of measured and simulated radiances}

From the CIMEL measurements we find $\Lambda=L\left(4^{\circ}\right) / L\left(3^{\circ}\right)$ $=0.856$ at $\lambda=1020 \mathrm{~nm}$. We assume an uncertainty of \pm 0.007 for $\Lambda$ which corresponds to an uncertainty of $\pm 0.05^{\circ}$ for the angular distance between the $L\left(3^{\circ}\right)$ - and the $L\left(4^{\circ}\right)$ measurement. $0.05^{\circ}$ is given by Holben et al. (1998) as the pointing precision of the Sun photometer.

In Fig. 9 simulated $\Lambda$ are plotted over the effective radius $r_{\text {eff }}$ of the ash. The results of all radiative transfer simulations in comparison to the measurement (horizontal lines) are shown. The colors are explained in the figure caption and indicate the different forms of the size distributions as defined in Table 4 and Fig. 8. Grey points denote spherical particles, for comparison. For each of the four forms of size

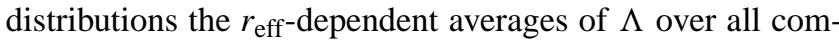
binations of the other model parameters $\left(m_{\mathrm{r}}, m_{\mathrm{i}}\right.$, shape, $\alpha$, boundary layer properties) are connected by dashed lines of the corresponding color. Black dotted lines show the resulting uncertainty range from all simulations with non-spherical ash particles.

Figure 9 shows that $\Lambda$ decreases with $r_{\text {eff }}$ of the ash particles. For SD\#1 (red color) we find, e.g., $0.932 \leq \Lambda \leq 0.944$ with an average of $\Lambda=0.937$, when $r_{\text {eff }}=0.8 \mu \mathrm{m}$, but only $0.680 \leq \Lambda \leq 0.711$ for $r_{\text {eff }}=3.0 \mu \mathrm{m}$. For the other forms of size distributions, $\Lambda$ is smaller for same $r_{\text {eff }}$, in particular, if bi-modal size distributions are considered (blue and brown color). The sensitivity of $\Lambda$ to changes of the form of the particle size distribution is typically of the order of 0.1 , when SD\#1 and SD\#4 are compared. For a given size distribution of the ash particles, the sensitivity of $\Lambda$ to changes of 


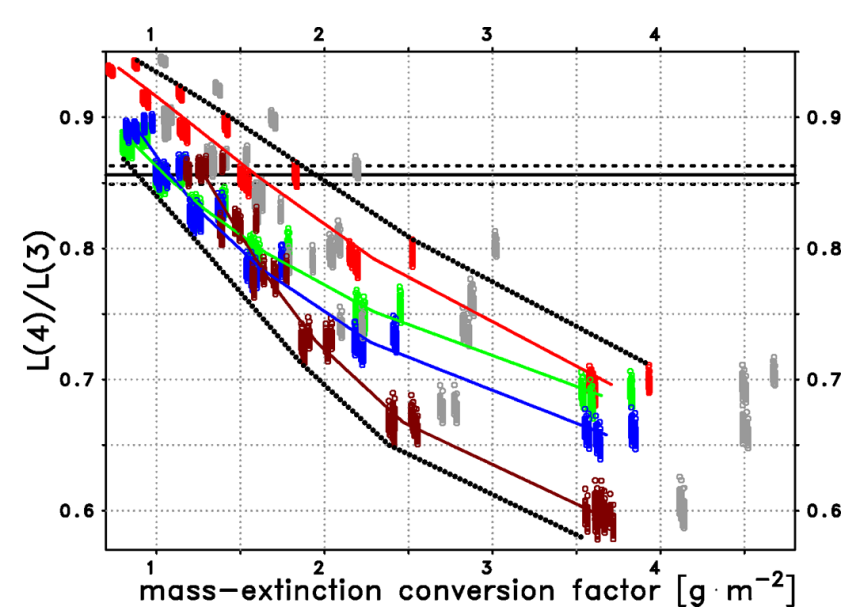

Fig. 10. Simulated ratios of aureole radiances $\Lambda=L\left(4^{\circ}\right) / L\left(3^{\circ}\right)$ at $\lambda=1020 \mathrm{~nm}$ over mass-extinction conversion factor $\eta$ of ash particles at $\lambda=532 \mathrm{~nm}$; red, green, blue, brown: non-spherical ash with SD\#1 to SD\#4; grey: spherical ash; black dotted: uncertainty range from simulations with non-spherical ash; horizontal lines: CIMEL measurement with uncertainty.

the other aerosol properties is quite low. In the hypothetical case of spherical ash particles (grey color), $\Lambda$ is only slightly larger than in the cases with non-spherical ash.

The results show that agreement of the modeled and measured $\Lambda$ is possible for $0.75 \mu \mathrm{m} \leq r_{\text {eff }} \leq 1.7 \mu \mathrm{m}$. These findings are in good agreement with the retrieval based on the lidar measurements as shown in Fig. 4.

In Fig. $10 \Lambda$ is plotted as a function of the mass-extinction conversion factor $\eta$ at $\lambda=532 \mathrm{~nm}$. As a consequence, each colored bar from Fig. 9 splits into at least three bars according to shape A, B and C. The reason is that according to Eq. 11, $\eta$ not only depends on $r_{\text {eff }}$ but also on shapedependent parameters $\overline{\xi_{\mathrm{vc}}^{3}}$ and $\overline{q_{\mathrm{ext}}}$. Thus, Fig. 10 was selected to illustrate the influence of the particle shape. For example, for $r_{\text {eff }}=2.0 \mu \mathrm{m}$ and SD\# $1(\Lambda \approx 0.80$, red bar in Fig. 9) we get values of $\eta=2.52 \mathrm{~g} \mathrm{~m}^{-2}, \eta=2.16 \mathrm{~g} \mathrm{~m}^{-2}$, or $\eta=2.19 \mathrm{~g} \mathrm{~m}^{-2}$, depending on whether particle shape A, B, or $\mathrm{C}$ is assumed; in case of spherical ash, the conversion factor would be considerably larger with $\eta=3.02 \mathrm{~g} \mathrm{~m}^{-2}$ (grey bar).

For mass-extinction conversion factors $\eta$ between $0.9 \mathrm{~g}$ $\mathrm{m}^{-2}$ and $2.0 \mathrm{~g} \mathrm{~m}^{-2}$ agreement between simulated and measured $\Lambda$ is found, as can seen from the black dotted lines. This range is in good agreement with the values retrieved from the lidar data. For comparison, if spherical ash particles are assumed, the range of $\eta$ is found to be from $1.2 \mathrm{~g} \mathrm{~m}^{-2}$ to $2.5 \mathrm{~g} \mathrm{~m}^{-2}$ (derived from the envelope of all results for spherical particles, grey bars).

\subsection{Discussion of results using sky radiances}

In the previous section we have found that $0.75 \mu \mathrm{m} \leq$ $r_{\text {eff }} \leq 1.7 \mu \mathrm{m}$ fits the aureole measurements. For a better un-

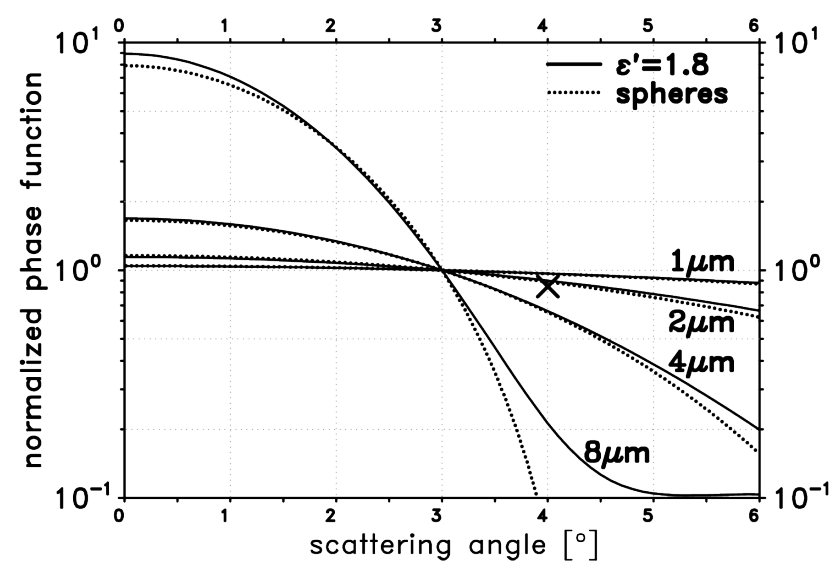

Fig. 11. Normalized phase functions $F_{11}(\theta) / F_{11}\left(3^{\circ}\right)$ in forward scattering direction from $\theta=0^{\circ}$ to $\theta=6^{\circ}$ of prolate spheroids and spheres with varying cross-section-equivalent radii $r_{\mathrm{c}} ; \lambda=1020 \mathrm{~nm}$; $m=1.56+0.0043 i$; cross: CIMEL measurement.

derstanding of this finding we want to briefly discuss a few of the underlying physical principles.

The discussion of $\Lambda$ is facilitated if we use single scattering properties of the ash particles, i.e. the ratio of their phase function $\Lambda_{11}=F_{11}\left(4^{\circ}\right) / F_{11}\left(3^{\circ}\right)$, as an approximation for $\Lambda$. This approach is possible because the radiances in the aureole are dominated by single forward scattering; in all simulations $\left|\Lambda-\Lambda_{11}\right|<0.17 \times(1-\Lambda)$. E.g., for the simulated $\Lambda$ that agrees with the measurement $(0.856 \pm 0.007)$, the difference $\left|\Lambda-\Lambda_{11}\right|$ is always smaller than 0.02 . Thus, we can use $\Lambda_{11}$ for further discussions.

First, we investigate the dependence of the forward scattering of a particle on its size. In Fig. 11 normalized phase functions $F_{11}(\theta) / F_{11}\left(3^{\circ}\right)$ at $\lambda=1020 \mathrm{~nm}$ are shown. For particles with radii of $1 \mu \mathrm{m}$ the phase function $F_{11}$ is almost constant in the forward scattering direction, i.e. for $\theta<6^{\circ}$ the ratio $F_{11}(\theta) / F_{11}\left(3^{\circ}\right)$ is close to 1 . With increasing particle size, the angular dependence of $F_{11}$ increases and the ratio $\Lambda_{11}$ decreases. For particle sizes of about $r=2.6 \mu \mathrm{m}, \Lambda_{11}$ is 0.856 which is consistent with $\Lambda$ derived from the CIMEL measurements (cross in Fig. 11). For larger particles the ratio $\Lambda_{11}$ is significantly smaller, e.g., $\Lambda_{11}=0.66$ for $r=4 \mu \mathrm{m}$, and for $r=8 \mu \mathrm{m}$ we get $\Lambda_{11}=0.21$. That is a clear indication that the observed volcanic ash over Munich was not dominated by particles in that size range.

To investigate the shape dependence of the diffraction peak, in Fig. 11 normalized phase functions of prolate spheroids $\left(\epsilon^{\prime}=1.8\right.$, solid lines $)$ and of spheres with the same cross-section-equivalent radius $r_{\mathrm{c}}$ (dotted lines) are compared. Figure 11 shows that the shape dependence of the main diffraction peak is much weaker than its dependence on particle size. The main difference is that for non-spherical particles the diffraction peak is slightly broader than for spheres, in particular for larger particles. This is clearly seen 


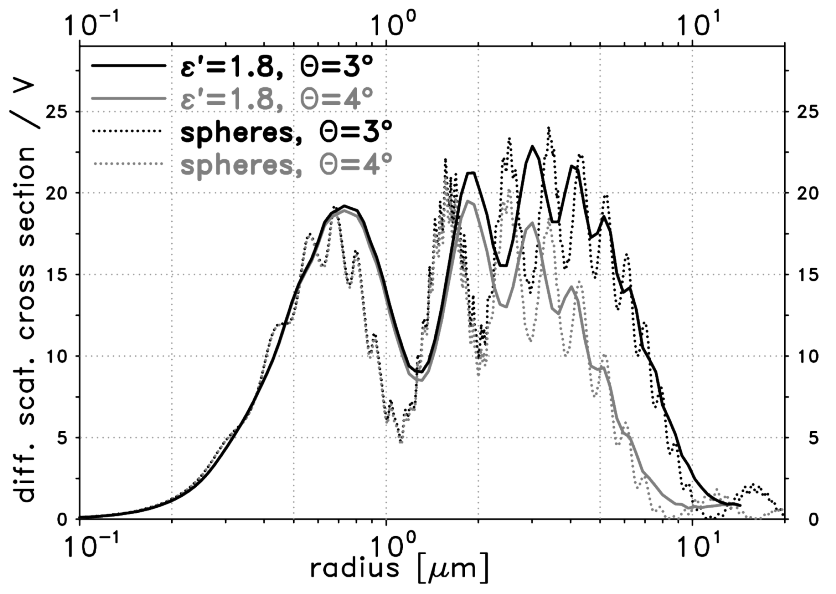

Fig. 12. Differential scattering cross section per particle volume $\left(C_{\mathrm{sca}} \times F_{11}(\theta) / V\right.$, arbitrary scale $)$ over cross-sectionequivalent radius $r_{\mathrm{c}}$ of prolate spheroids and spheres; $\lambda=1020 \mathrm{~nm}$; $m=1.56+0.0043 i$.

from Fig. 11, e.g., for $r=4 \mu \mathrm{m}$ and $\theta>5^{\circ}$. However, the shape dependence does not affect our conclusions with respect to the size of the particles that is in agreement with the aureole measurements.

For atmospheric aerosols the scattering contributions of particles of different sizes have to be weighted according to their size distribution. Figure 12 shows differential scattering cross sections per particle volume, i.e. $C_{\mathrm{sca}} \times F_{11}(\theta) / V$, at $\theta=3^{\circ}$ (solid) and $\theta=4^{\circ}$ (dashed) as a function of particle radius. Weighting of these curves with one of the particle volume distributions shown in Fig. 8 allows one to calculate $\Lambda_{11}$ for this volume distribution. According to Fig. 12 primarily the volume in particles with radii from approximately $0.3 \mu \mathrm{m}$ to $10 \mu \mathrm{m}$ contributes to scattering at $\theta=3^{\circ}$. In the range from $2 \mu \mathrm{m}$ to $10 \mu \mathrm{m}$ the sensitivity of $\Lambda_{11}$ to particle volume is much higher than for the lidar retrieval, which is immediately clear from comparison of Figs. 6 and 12. But for particles with $r>10 \mu \mathrm{m}$, the ratio $\Lambda_{11}$ is virtually insensitive. However, there are no indications from independent measurements or from transport modeling, that such particles were present over Munich during the case under investigation.

Table 5 shows the effective radii $r_{\text {eff }}$ that are consistent with the CIMEL measurement for the different forms of the size distributions (SD\#1 to SD\#4). The $r_{\text {eff }}$ are derived from Fig. 9 as the intercepts of the dotted lines with the measured $\Lambda$-value (horizontal line). It can be seen that the effective radii $r_{\text {eff }}$ that are in agreement with the radiance measurements depend on the forms of the size distribution; larger $r_{\text {eff }}$ are necessary for narrow size distributions (SD\#1) than for wide size distributions (e.g. SD\#2). For the compatible $r_{\text {eff }}$, Table 5 also shows the relative volume in particles with radii larger than certain radii. We find that the volume in particles with $r>2.5 \mu \mathrm{m}$ is approximately $25 \%$ of the total volume,
Table 5. Relative volume in particles larger than specific crosssection-equivalent radii; effective radius $r_{\text {eff }}$ is extracted from Fig. 9 (see text for details).

\begin{tabular}{lllll}
\hline SD & \multirow{2}{*}{$r_{\text {eff }}$} & \multicolumn{3}{c}{ relative volume in particles with } \\
& & $r>2.5 \mu \mathrm{m}$ & $r>5 \mu \mathrm{m}$ & $r>10 \mu \mathrm{m}$ \\
\hline$\# 1$ & $1.47 \mu \mathrm{m}$ & $27 \%$ & $3.7 \%$ & $0.1 \%$ \\
$\# 2$ & $0.98 \mu \mathrm{m}$ & $26 \%$ & $7.7 \%$ & $1.3 \%$ \\
$\# 3$ & $1.01 \mu \mathrm{m}$ & $26 \%$ & $4.2 \%$ & $0.2 \%$ \\
$\# 4$ & $0.82 \mu \mathrm{m}$ & $25 \%$ & $3.5 \%$ & $0.1 \%$ \\
\hline
\end{tabular}

nearly independent of the assumed size distribution. The uncertainty range for that value, as a result of the uncertainty of the aerosol parameters (Table 4) and the measurement uncertainty, is from $20 \%$ to $34 \%$.

As mentioned, the shape dependence of $\eta$ (Fig. 10) is a result of the proportionality between the mass-extinction conversion factor $\eta$ and the cube of the shape-dependent radius conversion factor $\overline{\xi_{\mathrm{vc}}^{3}}$ (Eq. 11). For the complex-shaped particles in Fig. 7, $\xi_{\mathrm{vc}}^{3}$ is 0.81 (a), 0.66 (b), and 0.65 (c), respectively, whereas for spherical particles $\xi_{\mathrm{vc}}^{3}$ is equal to one. An overestimation of the mass concentration by up to $50 \%$ may occur, if those particles were observed, but spheres were assumed for the interpretation of the observations. For vesicular ash particles $\overline{\xi_{\mathrm{vc}}^{3}}$ would be even smaller than 0.5 , and a significant overestimation of the mass would occur if vesicularity of the ash was not considered. Electron microscopy images of ash particles provide valuable information for an estimation of $\overline{\xi_{\mathrm{vc}}^{3}}$. The samples for the ash plume from Eyjafjallajökull (Schumann et al., 2010b) indicate that most of the particles were non-vesicular, thus we are confident that the $\overline{\xi_{\mathrm{vc}}^{3}}$ of our model particles (Fig. 7) are not unrealistic.

\section{Summary and conclusions}

The volcanic ash plumes from Eyjafjallajökull in spring 2010 over Europe provide an excellent opportunity for characterizing aerosol particles, testing scattering theory, and improving remote sensing techniques. However, the volcanic event also had an immediate and strong impact on transportation and economy as the mass concentration $M$ of volcanic ash is relevant for flight safety. Thus, advances of the methods for the determination of this parameter are urgently required.

In this paper, we investigated the possibility to retrieve the mass concentration of long-range transported volcanic ash, not mixed with other aerosol types, from lidar measurements by means of microphysical inversion. As input, a set of quality-controlled optical properties of the ash layer was available from lidar measurements, i.e. extinction coefficients, backscatter coefficients, and linear depolarization ratios at different wavelengths. The non-sphericity of the 
ash particles was explicitly considered in the retrieval by spheroids.

For the ash plume of 17 April 2010 over Maisach we found from our lidar retrieval a median of $1.45 \mathrm{~g} \mathrm{~m}^{-2}$ for the mass-extinction conversion factor $\eta$ at $\lambda=532 \mathrm{~nm}$. The uncertainty range (95\% of the retrieval solutions) was $\left(0.87 \cdot .2 .32 \mathrm{~g} \mathrm{~m}^{-2}\right)$. Due to the limited information content of the lidar data, the uncertainty of the inversion results was quite large. For the maximum of the ash plume over Maisach, which occurred in the morning of 17 April 2010, the lidar retrieval suggested a mass concentration $M$ of $1.1 \mathrm{mg} \mathrm{m}^{-3}$ $\left(0.65 \cdot 1.8 \mathrm{mg} \mathrm{m}^{-3}\right)$, averaged over one hour. Though shortterm maxima of $M$ might be slightly higher than the onehour-average, we conclude that the maximum mass concentration over Maisach was close to but probably not above $2 \mathrm{mg} \mathrm{m}^{-3}$, which is currently considered as the upper limit for "areas of low contamination" (International Civil Aviation Organization, 2010).

Model calculations showed that lidar signals are hardly sensitive to large particles $(r \gtrsim 3 \mu \mathrm{m})$, which may contain a significant portion of mass. To provide more confidence in the results of the lidar retrieval, we use co-located sky radiance measurements in the aureole of the Sun as an independent data set, which is sensitive to particles up to $r \approx 10 \mu \mathrm{m}$. From the exploitation of spectral sky radiances at two scattering angles we found a range for $\eta$ from 0.9 to $2.0 \mathrm{~g} \mathrm{~m}^{-2}$ for the ash over Munich. This confirms our retrieved mass concentrations from the lidar data. The sky radiance measurements indicate that approximately $75 \%$ of the mass was in ash particles with cross-section-equivalent radii smaller than $2.5 \mu \mathrm{m}$. The presence of particles with radii larger than $10 \mu \mathrm{m}$ cannot be excluded by the radiance measurements. The absence of significant amounts of such large particles in the observed plume, however, is confirmed by transport modeling.

An increase of the accuracy of the retrieval of $M$ can be expected from thorough and synergistic exploration of all available information from lidar and Sun photometer measurements, e.g., including sky radiances at all measurement wavelengths and scattering angles. Benefits could also be expected from further improvements of the aerosol models, and from observations at longer wavelengths, as they increase the sensitivity to large particles. The consideration of the non-sphericity of the ash particles is necessary for at least two reasons: First, the relevant optical properties are shape-dependent, particularly in case of lidar measurements. Second, particle volume tends to extinct more light with increasing non-sphericity. Thus, the assumption of spherical particles in a retrieval would lead to an overestimation of the volume and the mass of ash particles, provided that the crosssection-equivalent particle size is retrieved correctly. In that sense, spheres can provide an upper limit of the mass density, the "worst case".

In the course of volcanic eruptions, measurements of extinction coefficient $\alpha$ and linear depolarization ratio $\delta_{1}$ can provide the basis for estimating the ash mass concentrations in volcanic aerosol layers. If $\delta_{1}$ is low, or if $\delta_{1}$ is high but $\alpha$ is low, no ash-related flight safety impacts are expected. With increasing $\alpha$ of an ash layer (characterized by high $\delta_{1}$ ), the mass-extinction conversion factor $\eta$ becomes relevant for the assessment whether critical thresholds of ash mass concentrations $M$ are exceeded or not. In case of mixtures of ash with other types of aerosols, type separation techniques are required. For a robust estimate of $\eta$, high quality lidar measurements in combination with sky radiance measurements are useful, as discussed above. In general, however, such estimates can not be provided in near real-time; for a near real-time estimate of $M$, the development of a parameterization of $\eta$, possibly depending on parameters like transport time and eruption type, is recommended. For the parameterization of $\eta$, it is most important to understand the size distribution of the ash at emission and its changes during the atmospheric transport, because $\eta$ is highly correlated with the effective particle size. In doing so, a reliable (and probably large) uncertainty range of the parameterized $\eta$ has to be considered. The upper limit of $\eta$ is most critical in this context because, if $\eta$ is underestimated, flights may get into problems. Note, that the implications might also be different for different types of jet engines. To get the spatial distribution of an ash plume and to monitor its dispersion, for example on continental scale, the operation of a network of lidars such as EARLINET is recommended. Secondary networks of ceilometers that are currently implemented by national weather services help to improve the spatial coverage.

Acknowledgements. The financial support for the improvement of the EARLINET infrastructure by the European Commission under grant RICA-025991 is gratefully acknowledged. This work was partially funded by the Deutsche Forschungsgesellschaft (DFG) under grant number FOR 539 (SAMUM research group). We thank Bernhard Mayer, Ulrich Schumann, Gian Paolo Gobbi, Tomoaki Nishizawa, and both reviewers for their valuable comments on the paper.

Edited by: G. Pappalardo

\section{References}

Ansmann, A., Wandinger, U., Riebesell, M., Weitkamp, C., and Michaelis, W.: Independent measurement of extinction and backscatter profiles in cirrus clouds by using a combined Raman elastic-backscatter lidar, Appl. Opt., 31, 7113, doi:10.1364/AO.31.007113, 1992.

Ansmann, A., Tesche, M., Groß, S., Freudenthaler, V., Seifert, P., Hiebsch, A., Schmidt, J., Wandinger, U., Mattis, I., Müller, D., and Wiegner, M.: The 16 April 2010 major volcanic ash plume over central Europe: EARLINET lidar and AERONET photometer observations at Leipzig and Munich, Germany, Geophys. Res. Lett., 37, L13810, doi:10.1029/2010GL043809, 2010.

Bösenberg, J., Matthias, V., Amodeo, A., et. al.: EARLINET: A European Aerosol Research Lidar Network to Establish an Aerosol 
Climatology, Max-Planck-Institut Report No. 348, Hamburg, Germany, 2003.

Casadevall, T. J. (editor): Volcanic Ash and Avitation Safety: Proceedings of the First International Symposium on Volcanic Ash and Avitation Safety (US Geological Survey Bulletin 2047), Washington, USA, 1994.

Draxler, R. R. and Rolph, G. D.: HYSPLIT (HYbrid Single-Particle Lagrangian Integrated Trajectory) Model access via NOAA ARL READY Website, available online at: http://ready.arl.noaa.gov/ HYSPLIT.php, NOAA Air Resources Laboratory, Silver Spring, MD, USA, 2010.

Dubovik, O., Sinyuk, A., Lapyonok, T., Holben, B. N., Mishchenko, M., Yang, P., Eck, T. F., Volten, H., Muñoz, O., Veihelmann, B., van der Zande, W. J., Leon, J., Sorokin, M., and Slutsker, I.: Application of spheroid models to account for aerosol particle nonsphericity in remote sensing of desert dust, J. Geophys. Res., 111, D11208, doi:10.1029/2005JD006619, 2006.

Fernald, F. G.: Analysis of atmospheric lidar observations: some comments, Appl. Opt., 23, 652-653, doi:10.1364/AO.23.000652, 1984.

Flentje, H., Claude, H., Elste, T., Gilge, S., Köhler, U., PlassDülmer, C., Steinbrecht, W., Thomas, W., Werner, A., and Fricke, W.: The Eyjafjallajökull eruption in April 2010 - detection of volcanic plume using in-situ measurements, ozone sondes and lidar-ceilometer profiles, Atmos. Chem. Phys., 10, 1008510092, doi:10.5194/acp-10-10085-2010, 2010.

Freudenthaler, V., Esselborn, M., Wiegner, M., Heese, B., Tesche, M., Ansmann, A., Müller, D., Althausen, D., Wirth, M., Fix, A., Ehret, G., Knippertz, P., Toledano, C., Gasteiger, J., Garhammar, M., and Seefeldner, M.: Depolarizationratio profiling at several wavelengths in pure Saharan dust during SAMUM 2006, Tellus B, 61, 165-179, doi:10.1111/j.1600-0889.2008.00396.x, 2009.

Gardner, G. Y.: Simulation of natural scenes using textured quadric surfaces, Proceedings of the 11th annual conference on Computer graphics and interactive techniques, 11-20, 1984.

Gertisser, R.: Eyjafjallajökull volcano causes widespread disruption of European air traffic, Geology Today, 26, 94-95, doi:10.1111/j.1365-2451.2010.00757.x, 2010.

Groß, S., Freudenthaler, V., Toledano, C., Seefeldner, M., and Wiegner, M.: Mini-lidar measurements of particle depolarization and Raman scattering of Saharan-dust and biomass burning at $355 \mathrm{~nm}$ during SAMUM 2, Proc. of 24th International Laser Radar Conference, Boulder, USA, 23-27 June 2008, S04P-10, 2008.

Groß, S., Freudenthaler, V., Gasteiger, J., Schnell, F., and Wiegner, M.: Characterization of the Eyjafjallajökull ash-plume by means of Lidar measurements over the Munich EARLINET-site, SPIE Conference, Toulouse, France, 20-23 September 2010, Paper 7832-20, 2010.

Herman, B. R., Gross, B., Moshary, F., and Ahmed, S.: Bayesian assessment of uncertainty in aerosol size distributions and index of refraction retrieved from multiwavelength lidar measurements, Appl. Opt., 47, 1617-1627, doi:10.1364/AO.47.001617, 2008.

Hess, M., Koepke, P., and Schult, I.: Optical Properties of Aerosols and Clouds: The Software Package OPAC, B. Am. Meteorol. Soc., 79, 831-844, 1998.

Holben, B. N., Eck, T. F., Slutsker, I., Tanr, D., Buis, J. P., Setzer, A., Vermote, E., Reagan, J. A., Kaufman, Y. J., Nakajima, T., Lavenu, F., Jankowiak, I., and Smirnov, A.:
AERONET - A Federated Instrument Network and Data Archive for Aerosol Characterization, Remote Sens. Environ., 66, 1-16, doi:10.1016/S0034-4257(98)00031-5, 1998.

International Civil Aviation Organization: EUR DOC 019 - Volcanic Ash Contingency Plan EUR and NAT Regions (1st Edition), available online at: http://www.paris.icao.int/documents_ open/show_file.php?id=334, 2010.

Jäger, H.: Long-term record of lidar observations of the stratospheric aerosol layer at Garmisch-Partenkirchen, J. Geophys. Res., 110, D08106, doi:10.1029/2004JD005506, 2005.

Kandler, K., Benker, N., Bundke, U., Cuevas, E., Ebert, M., Knippertz, P., Rodríguez, S., Schütz, L., and Weinbruch, S.: Chemical composition and complex refractive index of Saharan Mineral Dust at Izaña, Tenerife (Spain) derived by electron microscopy, Atm. Env., 41, 8058-8074, doi:10.1016/j.atmosenv.2007.06.047, 2007.

Macke, A. and Mishchenko, M. I.: Applicability of regular particle shapes in light scattering calculations for atmospheric ice particles, Appl. Opt., 35, 4291-4296, doi:10.1364/AO.35.004291, 1996.

Mather, T. A., Pyle, D. M., and Oppenheimer, C.: Tropospheric Volcanic Aerosol, in: Volcanism and the Earth's atmosphere, Geophysical monograph 139, edited by: Robock, A. and Oppenheimer, C., Am. Geophys. Union, Washington, DC, 189-212, 2003.

Mattis, I., Siefert, P., Müller, D., Tesche, M., Hiebsch, A., Kanitz, T., Schmidt, J., Finger, F., Wandinger, U., and Ansmann, A.: Volcanic aerosol layers observed with multiwavelength Raman lidar over central Europe in 2008-2009, J. Geophys. Res., 115, D00L04, doi:10.1029/2009JD013472, 2010.

Mayer, B.: Radiative transfer in the cloudy atmosphere, European Physical Journal Conferences, 1, 75-99, doi:10.1140/epjconf/e2009-00912-1, 2009.

Mayer, B. and Kylling, A.: Technical note: The libRadtran software package for radiative transfer calculations - description and examples of use, Atmos. Chem. Phys., 5, 1855-1877, doi:10.5194/acp-5-1855-2005, 2005.

Mishchenko, M. I. and Travis, L. D.: Capabilities and limitations of a current Fortran implementation of the T-Matrix method for randomly oriented, rotationally symmetric scatterers, J. Quant. Spectrosc. Radiat. Transfer, 60, 309-324, doi:10.1016/S00224073(98)00008-9, 1998.

Mishchenko, M. I., Travis, L. D., Kahn, R. A., and West, R. A.: Modeling phase functions for dustlike tropospheric aerosols using a shape mixture of randomly oriented polydisperse spheroids, J. Geophys. Res., 102, 16831-16847, doi:10.1029/96JD02110, 1997.

Mosegaard, K. and Tarantola, A.: Probabilistic approach to inverse problems, in: in International Handbook of Earthquake \& Engineering Seismology, Part A, Academic Press, 237-265, 2002.

Muñoz, O., Volten, H., Hovenier, J. W., Veihelmann, B., van der Zande, W. J., Waters, L. B. F. M., and Rose, W. I.: Scattering matrices of volcanic ash particles of Mount St. Helens, Redoubt, and Mount Spurr Volcanoes, J. Geophys. Res., 109, D16201, doi:10.1029/2004JD004684, 2004.

Müller, H. and Quenzel, H.: Information content of multispectral lidar measurements with respect to the aerosol size distribution, Appl. Opt., 24, 648-654, doi:10.1364/AO.24.000648, 1985.

Nakajima, T., Tanaka, M., and Yamauchi, T.: Retrieval of the opti- 
cal properties of aerosols from aureole and extinction data, Appl. Opt., 22, 2951-2959, doi:10.1364/AO.22.002951, 1983.

Patterson, E. M., Pollard, C. O., and Galindo, I.: Optical properties of the ash from El Chichon Volcano, Geophys. Res. Lett., 10, 317-320, doi:10.1029/GL010i004p00317, 1983.

Pieri, D., Ma, C., Simpson, J. J., Hufford, G., Grindle, T., and Grove, C.: Analyses of in-situ airborne volcanic ash from the February 2000 eruption of Hekla Volcano, Iceland, Geophys. Res. Let., 29, 1772, doi:10.1029/2001GL013688, 2002.

Sanderson, K.: Out of the ashes, Nature, 465, 544-545, doi:10.1038/465544a, 2010.

Sassen, K., Zhu, J., Webley, P., Dean, K., and Cobb, P.: Volcanic ash plume identification using polarization lidar: Augustine eruption, Alaska, Geophys. Res. Lett., 34, L08803, doi:10.1029/2006GL027237, 2007.

Schumann, U., Mayer, B., Gierens, K., Unterstrasser, S., Jessberger, P., Petzold, A., Voigt, C., and Gayet, J.-F.: Effective Radius of Ice Particles in Cirrus and Contrails, J. Atmos. Sci., doi:10.1175/2010JAS3562.1, in press, 2010a.

Schumann, U., Weinzierl, B., Reitebuch, O., et. al.: Airborne observations of the Eyjafjalla volcano ash cloud over Europe during air space closure in April and May 2010, Atmos. Chem. Phys. Discuss., 10, 22131-22218, doi:10.5194/acpd-10-22131-2010, 2010b.

Tarantola, A.: Popper, Bayes and the inverse problem, Nature Physics, 2, 492-494, doi:10.1038/nphys375, 2006.

Thomalla, E. and Quenzel, H.: Information content of aerosol optical properties with respect to their size distribution, Appl. Opt., 21, 3170-3177, doi:10.1364/AO.21.003170, 1982.
Valery, A., Cartwright, R., Fausett, E., Ossipov, A., Pasko, E., and Savchenko, V.: HyperFun project: a framework for collaborative multidimensional F-rep modeling, Eurographics/ACM SIGGRAPH Workshop Implicit Surfaces 99, Bordeaux, France, 1999.

van de Hulst, H. C.: Light Scattering by Small Particles, Dover Publications, New York, USA, 1981.

Wiegner, M., Gasteiger, J., Kandler, K., Weinzierl, B., Rasp, K., Esselborn, M., Freudenthaler, V., Heese, B., Toledano, C., Tesche, M., and Althausen, D.: Numerical simulations of optical properties of Saharan dust aerosols with emphasis on lidar applications, Tellus B, 61, 180-194, doi:10.1111/j.1600-0889.2008.00381.x, 2009.

Wiegner, M.: Potential of ceilometers for aerosol remote sensing: a preliminary assessment, Proc. of 25th International Laser Radar Conference, St. Petersburg, Russia, 5-9 July 2010, S07P-05, 2010.

Wiegner, M., Gasteiger, J., Groß, S., Schnell, F., Freudenthaler, V., and Forkel, R.: Characterization of the Eyjafjallajökull ashplume: Potential of lidar remote sensing, Phys. Chem. Earth, doi:10.1016/j.pce.2011.01.006, in press, 2011.

Yang, P. and Liou, K. N.: Light scattering by hexagonal ice crystals: solutions by a ray-by-ray integration algorithm, J. Opt. Soc. Am. A, 14, 2278-2289, doi:10.1364/JOSAA.14.002278, 1997.

Yurkin, M. A., Maltsev, V. P., and Hoekstra, A. G.: The discrete dipole approximation for simulation of light scattering by particles much larger than the wavelength, J. Quant. Spectrosc. Radiat. Transf., 106, 546-557, doi:10.1016/j.jqsrt.2007.01.033, 2007. 